Available online at https://jurnal.stmikroyal.ac.id/index.php/jurdimas

\title{
PELATIHAN PEMBUATAN MEDIA PEMBELAJARAN KIDDY LEARNING BINDER BAGI GURU PAUD
}

\author{
Ulfa Yuliasari ${ }^{1}$, Rista Dwi Permata ${ }^{2 *}$ \\ ${ }^{1}$ Prodi Pendidikan Bahasa Inggris, Universitas PGRI Ronggolawe Tuban \\ ${ }^{2}$ Prodi PG PAUD, Universitas PGRI Ronggolawe Tuban \\ email:*rista.permata.rp@gmail.com
}

\begin{abstract}
Through a workshop and coaching to make learning media, Kiddy Learning Binder aims to increase the knowledge and skills of early childhood teachers in making educative props in Pusaka KB/TK and Harapan Bangsa Kindergarten at Kecamatan Tuban Kabupaten Tuban. Kiddy Learning Binder is an educational teaching aid to intended as a media learning which to be easy in the process of teaching and learning activities. Based on the problem, according to the survey results obtained in the field that the learning media in PAUD institutions are still minimum, and most of skills PAUD teachers are lack to make learning media, they more often bought the learning media than innovate to make their own. The solution to this problem was solved by providing workshop to make Kiddy Learning Binder learning media in Pusaka KB/TK and Harapan Bangsa Kindergarten. The implementation phase of workshop and coaching begins with observation and permission to get society service partners. Next, identify the initial abilities and then implementation by providing material/theory explanations and conducting training practices, and finally the monitoring and evaluation stage by measuring the success of the media that has been made through the training provided.
\end{abstract}

Keywords: educative props; kiddy learning binder; media learning

\begin{abstract}
Abstrak: Melalui pendampingan dan pelatihan pembuatan media pembelajaran Kiddy Learning Binder ini bertujuan untuk meningkatkan pengetahuan dan keterampilan guru PAUD dalam membuat alat peraga edukatif di KB/TK Pusaka dan TK Harapan Bangsa Kecamatan Tuban Kabupaten Tuban. Kiddy Learning Binder merupakan alat peraga edukatif yang diperuntukkan sebagai media pembelajaran yang memudahkan proses kegiatan belajar mengajar. Didasarkan pada permasalahan, sesuai hasil survei yang diperoleh di lapangan bahwa media pembelajaran pada lembaga PAUD tersebut masih minim, serta sebagian besar guru PAUD kurang mempunyai keterampilan dalam membuat media pembelajaran, mereka lebih sering untuk membeli media pembelajaran daripada berinovasi untuk membuat sendiri. Solusi permasalahan ini dipecahkan dengan memberikan pelatihan pembuatan media pembelajaran Kiddy Learning Binder di KB/TK Pusaka dan TK Harapan Bangsa Kecamatan Tuban Kabupaten Tuban. Tahap pelaksanaan pendampingan dan pelatihan diawali dari observasi dan perijinan untuk mendapatkan mitra pengabdian kepada masyarakat. Selanjutnya, mengidentifikasi kemampuan awal lalu pelaksanaan dengan memberikan penjelasan materi/teori dan melakukan praktek pelatihan, serta yang terakhir tahap monitoring dan mengevaluasi dengan mengukur keberhasilan media yang telah dibuat melalui pelatihan yang diberikan.
\end{abstract}

Kata kunci: alat peraga edukatif; kiddy learning binder; media pembelajaran 
Available online at https://jurnal.stmikroyal.ac.id/index.php/jurdimas

\section{PENDAHULUAN}

Pendidikan anak usia dini merupakan jenjang pendidikan sebelum pendidikan dasar. Pendidikan anak usia dini adalah suatu proses yang dilakukan untuk membina tumbuh kembang anak usia baru lahir hingga enam tahun. Anak usia dini berada pada periode berfikir kongkret, artinya anak yang berada pada masa itu belum mampu berpikir diluar batas kemampuan panca inderanya (secara abstrak). Pemberian pengalaman belajar yang kongkret akan meningkatkan kebermaknaan dalam proses belajar anak (Eliyawati, 2005). Salah satu periode yang menjadi penciri masa usia dini adalah the golden age atau periode keemasan (Rahmawati, 2014). Pemberian stimulasi yang tepat kepada anak usia dini dapat menjembatani anak untuk lebih siap dalam memasuki pendidikan yang lebih tinggi, hal ini sesuai dengan landasan yuridis UU No. 20 tahun 2003 pasal 1 ayat 14 tentang Sistem Pendidikan Nasional (Suyadi, 2014).

Satuan pendidikan anak usia dini menyelenggarakan berbagai layanan pendidikan yang disesuaikan dengan kondisi dan kemampuan anak, baik jalur pendidikan formal maupun informal. Salah satu program jalur pendidikan formal bagi anak usia tiga sampai enam tahun yaitu pendidikan anak usia dini (PAUD). Pendidikan di usia dini adalah tahapan praoperasional yang mana pada tahap ini anak dapat memanipulasi objek simbol termasuk kata-kata yang merupakan karakteristik penting dalam tahapan ini (Yuliani Nurani \& Bambang, 2010).

Dukungan untuk fasilitas, sarana dan prasarana, media pembelajaran, ruang belajar, ruang bermain yang memadai serta suasana yang kondusif diperlukan dalam perkembangan diri anak didik di PAUD dengan menyesuaikan karakteristik anak agar proses pembelajaran yang diberikan guru untuk peserta didik di PAUD dapat berjalan dengan optimal. Pada anak usia dini karakteristik belajarnya adalah bermain, karena bermain merupakan bagian dari belajar. Menurut Moyles dalam (Safitri, Syukri \& Yuniarni, 2014) bermain merupakan suatu proses yang dibutuhkan oleh anakanak maupun orang dewasa karena bisa dilakukan untuk kepentingan diri sendiri dengan cara-cara yang menyenangkan . Usia 3-6 tahun merupakan masa usia keemasan bagi perkembangan kepribadian anak. Pemberian stimulus dan latihan-latihan pada perkembangan anak sebaiknya diberikan sejak dini karena hal tersebut untuk merangsang dan memaksimalkan pertumbuhan serta perkembangan pada anak.

Dalam hal ini, guru harus terampil dan kreatif dalam proses pembelajaran di PAUD agar belajar dan mengajar bisa berjalan dengan efektif, bisa memikat perhatian, sehingga anak berminat dan muncul rasa keingintahuannya dan pastinya bisa membuat suasana menjadi menyenangkan. Salah satu faktor yang perlu diperhatikan guru ialah media atau alat bermain yang beragam sebagai sarana untuk membangkitkan motivasi anak dalam kreativitas. Menurut Arda dkk (Wulandari, 2016) media menjadi salah satu faktor untuk mendukung keberhasilan proses pembelajaran di sekolah karena dapat membantu sebagai saluran untuk menyampaikan informasi dari guru kepada siswa ataupun sebaliknya. Penggunaan media secara kreatif dapat menciptakan berbagai suasana di kelas sehingga akan menyenangkan dan meningkatkan efisiensi pembelajaran sehingga tujuan pembelajaran dapat tercapai. Seorang guru dapat mengembangkan metode pembelajaran juga di harapkan dapat 
Available online at https://jurnal.stmikroyal.ac.id/index.php/jurdimas

memanfaatkan media yang digunakan sesuai dengan metode, karakteristik dan berbagai jenis media yang disesuaikan dengan tujuan pembelajaran yang ingin dicapai. Untuk pemanfaatan media dalam proses pembelajaran dapat memudahkan guru dan membantu menyampaikan materi yanag akan diajarkan kepada anak.

Saat ini, perkembangan media dalam proses pembelajaran anak seusia PAUD sangatlah beraneka ragam jenisnya sesuai karakteristik yang dibutuhkan, salah satunya adalah media pembelajaran Kiddy Learning Binder. Menurut Kamus Besar Bahasa Indonesia (Daring, 2016), Kiddy atau kanak-kanak adalah periode perkembangan anak masa pra-sekolah (usia antara 2-6 tahun). Learning atau pembelajaran menurut Kamus Besar Bahasa Indonesia (Daring, 2016), yaitu proses, cara, perbuatan menjadikan belajar. Sedangkan Binder adalah menjilid buku, majalah, dan sebagainya. Dari pengertian tersebut dapat kita artikan bahwa Kiddy Learning Binder adalah media pembelajaran interaktif berupa buku yang dijilid sedemikian rupa dengan didalamnya terdapat cerita menarik bagi anak dengan dibumbuhi kegiatan yang bisa menstimulasi motorik halus anak. Dengan menggunakan berbagai bahan yang berwarna warni dengan warna-warna cerah serta aman bagi anak mampu merangsang aspek perkembangan anak diantaranya kognitif, bahasa, motorik halus dan lain-lain.

Kiddy Learning Binder merupakan kombinasi dari media pembelajaran Busy Book dan buku cerita bergambar. Dalam pengertiannya, Busy book adalah sebuah media pembelajaran, semacam mainan bagi anak-anak yang berbentuk buku interaktif yang terbuat dari kain flanel yang dibentuk menjadi sebuah buku dengan menggunakan berbagai warnawarni, berisi aktivitas kegiatan permainan sederhana agar merangsang aspek perkembangan anak antara lain kognitif dan motorik halus contohnya pada aktivitas memasang kancing, mencocokkan warna atau bentuk, menempel, dan lainlain. Manfaat busy book antara lain yaitu dengan ketrampilan guru dalam membuat media ini maka dapat dijadikan materi ajar yang sistematis sehingga pembelajaran menjadi lebih maksimal, menyenangkan dan tidak monoton. Media ini dapat dijadikan alternatif untuk media pembelajaran bagi guru PAUD karena berfungsi sebagai media pembelajaran yang menyenangkan untuk anak (Mufliharsi, 2017).

Sedangkan media buku cerita merupakan buku yang di dalamnya memuat teks bacaan dan gambar-gambar yang keduanya saling berkaitan untuk membentuk suatu cerita. Buku cerita bergambar biasanya dapat merangsang perkembangan kognitif, bahasa, imajinasi, dan lain sebagainya. Buku cerita bergambar memiliki manfaat dapat merangsang dan menarik minat peserta didik untuk membaca serta dapat membantu peserta didik untuk dapat memahami isi cerita melalui tulisan yang didukung dengan ilustrasi (Farendra, 2018).

Karena pada saat usia dini, perkembangan otak berkembang dengan pesatnya, maka diperlukan media pembelajaran yang mampu memberikan berbagai kegiatan sehingga dapat meningkatkan kemampuan dalam diri anak. Berdasarkan hal tersebut, maka muncul ide untuk menggabungkan antara media busy book dan cerita bergambar dengan tujuan agar aspek perkembangan yang terstimulasi lebih luas, yaitu kognitif, motorik halus, bahasa, dan kreativitas anak. Penggabungan ini diwujudkan dalam bentuk media Kiddy Learning Binder yang didalamnya terdapat kegiatan- 
Available online at https://jurnal.stmikroyal.ac.id/index.php/jurdimas

kegiatan layaknya busy book ditambah alur cerita yang mampu menstimulasi bahasa anak, khususnya kosakata dan perintah sederhana.

\section{METODE}

Kegiatan ini dilaksanakan di KB/TK Pusaka dengan jumlah peserta 15 orang dari pendidik di KB/TK Pusaka dan TK Harapan Bangsa Tuban. Metode pelaksanaan pengabdian masyarakat ini adalah Pendidikan Masyarakat, ada 3 tahapan kegiatan yaitu tahap persiapan, tahap pelaksanaan, dan tahap monitoring untuk mengevaluasi. Di tahap persiapan antara lain survey, menentukan sasaran lokasi untuk mendapatkan mitra lembaga, membuat proposal kegiatan, menyiapkan surat ijin pada mitra lembaga, penyusunan bahan dan materi pelatihan, yang meliputi: contoh produk kiddy learing binder, alat dan bahan, panduan pelatihan dan materi powerpoint untuk kegiatan pelatihan.

Pada tahap pelaksanaan terdiri dari penjelasan terkait media pembelajaran secara umum, penjelasan tentang manfaat media kiddy learning binder, dan pelatihan dalam pembuatan media pembelajaran kiddy learning binder. selanjutnya tahap terakhir yaitu monitoring serta mengevaluasi selama proses pelatihan dengan mengamati dan memeriksa untuk mengukur keberhasilan hasil karya media kiddy learning binder yang telah dibuat yang setelahnya akan dipresentasikan satu per satu agar semua mengetahui indikator keberhasilan pada masing-masing kelompok.

\section{PEMBAHASAN}

Kegiatan ini telah dilaksanakan di ruang pertemuan KB/TK Pusaka pada minggu ke-2 bulan September tahun 2020 dengan 3 pertemuan sesuai dengan perjanjian dari kedua lembaga.

Kegiatan pelatihan pada pertemuan pertama diawali dengan penyampaian materi yang dilakukan oleh ketua dan anggota pengabdian masyarakat sebagai narasumber. Dalam hal ini, narasumber memberikan pengantar tentang Kiddy Learning Binder secara gambaran umum, kemudian teknik pembuatannya dengan dibantu oleh dua mahasiswa untuk pelaksanaannya. Lalu dilanjutkan dengan membagi kelompok masingmasing terdiri dari 3 orang guru. Tiaptiap kelompok berdiskusi untuk menentukan konsep kiddy learning binder oleh peserta yang terdiri dari tema, isi alur cerita tema, konsep kegiatan serta alat dan bahan yang diperlukan. Setelah konsep tema sudah ditentukan, masingmasing kelompok perserta diberikan alat dan bahan yang sudah disediakan oleh tim pengabdian masyarakat yang terdiri dari kain flannel, alat lem tembak beserta lem tembaknya, karton, gunting aneka manik-manik, aksesoris mata, velcro, pita satin kecil, plastik mika, jarum pentul, resleting, tali kur dan kancing.

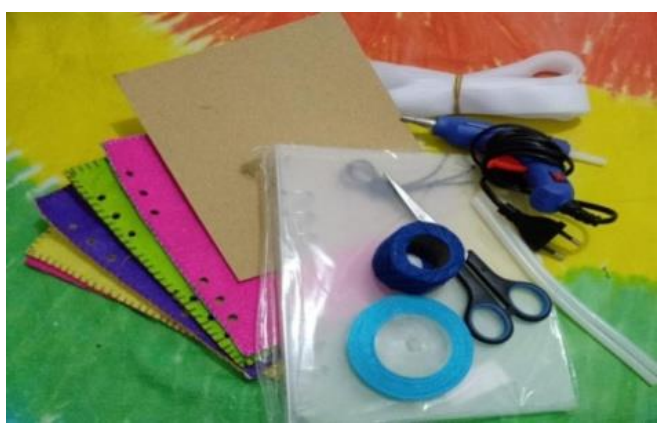

Gambar 1. Alat dan bahan pembuatan media kiddy learning binder

Pada pertemuan kedua, peserta pelatihan yang telah dibagi kelompok yang terdiri dari dua orang guru akan mulai membuat media kiddy learning binder dengan tema dan alur cerita yang telah 
Available online at https://jurnal.stmikroyal.ac.id/index.php/jurdimas

ditentukan bersama anggota kelompoknya pada pertemuan sebelumnya. Dan penyelesaiannya dilakukan dirumah dikarenakan keterbatasan waktu yang tersedia dengan membawa pulang alat dan bahan yang telah dibagikan oleh tiap kelompok peserta yang nantinya bisa digunakan kembali untuk menyelesaikan kiddy learning binder.

Pada pertemuan ketiga, para peserta mempresentasikan hasil dari pembuatan media kiddy learning binder sesuai dengan tema dan alur cerita yang telah ditentukan masing-masing kelompok. Karya kiddy learning binder yang dibuat oleh para guru ini sangat beragam, kreatif, menggunakan kosakata yang mudah diingat anak-anak dan menarik karena menggunakan warnawarna yang cerah sehingga anak terdorong rasa untuk ingin tahu untuk belajar. Media ini menggunakan alur cerita yang bermacam-macam judul dan tema, antara lain cerita tentang aktivitas sehari-hari, berkebun, perkembangbiakan hewan serta tamasya ke kebun binatang.

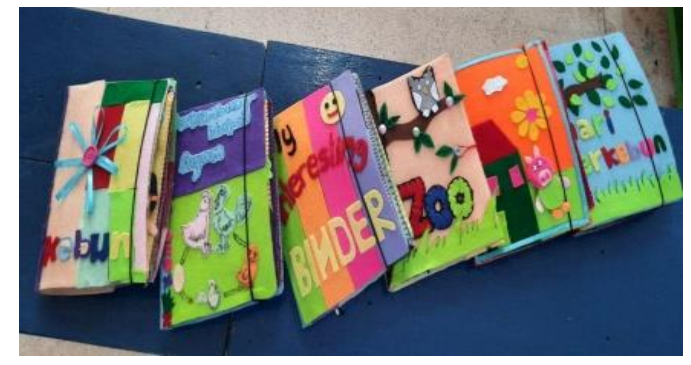

Gambar 2. Hasil Karya Para Guru pada Pelatihan Pembuatani Kiddy Learning Binder

Pembuatan media pembelajaran ini dapat membantu proses pembelajaran di kedua lembaga PAUD tersebut dikarenakan media kiddy learning binder ini merupakan media pembelajaran edukatif yang menggabungkan antara media busy book dan buku cerita bergambar dimana kedua media tersebut sangat sesuai dengan kebutuhan belajar pada anak usia dini. Pada penelitian yang dijelaskan oleh (Reed, Hurks, Kirschner, \& Jolles, 2015), bahwa bercerita melalui buku cerita bergambar dalam kelompok teman sebaya dapat menstimulasi penalaran bagi anak usia 4,5 sampai 6 tahun karena gambar dalam buku cerita lebih efektif bagi anak dalam memahami cerita dibandingkan dengan cerita yang hanya berisi teks saja. Keunggulan media seperti Busy book menurut (Daryanto, 2018) bisa digunakan untuk semua tema dengan dibuat sendiri sesuai keinginan kita dalam berkreasi, pada setiap gambarnya bisa diatur sendiri, bisa menyesuaikan dengan kebutuhan anak, dapat dipergunakan berkalikali, menghemat waktu dan tenaga. Sehingga keterlibatan anak akan terlihat dari keaktifan anak dalam kegiatan pemainan media kiddy learning binder untuk saling bekerjasama satu sama lainnya. Seperti yang dipaparkan (Ulfah \& Rahmah, 2017) bahwa dengan adanya media busy book yang disertai dengan aktifitas permainan dapat memotivasi anak usia dini dalam belajar membaca dan belajar akan jauh lebih menyenangkan bagi anak.

\section{SIMPULAN}

Setelah mengikuti pelatihan dan pembuatan media pembelajaran Kiddy Learning Binder dengan sangat antusias, para guru sangat terlihat aktif dan terampil untuk langsung mempraktekkannya. Dari kegiatan pelatihan pembuatan media pembelajaran berupa Kiddy Learning Binder ini, para guru sudah terampil dalam berkreasi. Selain itu, umpan balik yang diberikan para guru kepada tim pengabdian masyarakat yaitu para guru sangat senang dengan adanya pelatihan ini karena bisa menambah pengetahuan baru serta dapat 
Available online at https://jurnal.stmikroyal.ac.id/index.php/jurdimas

lebih terampil dalam pembuatan media pembelajaran. Setelah diadakannya kegiatan pengabdian masyarakat ini, dapat kita ketahui bahwa masih ada lembaga KB/TK dan PAUD yang sangat memerlukan media pembelajaran yang bisa dibuat sendiri, tanpa memerlukan bahan yang mahal maupun susah dicari dan tentunya aman bagi anak-anak dalam upaya untuk membantu guru melaksanakan kegiatan pembelajaran.

\section{DAFTAR PUSTAKA}

Daring, K. (2016). Badan Pengembangan dan Pembinaan Bahasa, Kementerian Pendidikan dan Kebudayaan Republik Indonesia. Tersedia Di: Http://Kbbi. Kemdikbud. Go. Id/Entri/Terampil.[Diakses: JuniNovember 2016].

Daryanto. (2018). Penelitian Tindakan Kelas dan Penelitian Tindakan Sekolah. Gava Media.

Eliyawati, C. (2005). Pemilihan dan pengembangan sumber belajar untuk anak usia dini. Jakarta: Depdiknas.

Farendra, M. F. (2018). Pengembangan Buku Cerita Bergambar untuk Literasi Pembelajaran SAINS di Sekolah Dasar. Repository Unja. https://repository.unja.ac.id/4623/1 /Mas Fitra Farenda_A1D114040_Artikel -.pdf Mufliharsi, R. (2017). Pemanfaatan busy book pada kosakata anak usia dini di paud swadaya Pkk. Metamorfosa Journal, 5(2), 146155.

Rahmawati, N. (2014). Pengaruh Media
Pop-Up Book Terhadap Penguasaan Kosakata Anak Usia 5-6 Tahun Di TK Putera Harapan Surabaya. PAUD Teratai, 3(1).

Reed, H. C., Hurks, P. P. M., Kirschner, P. A., \& Jolles, J. (2015). Preschoolers' causal reasoning during shared picture book storytelling: A cross-case comparison descriptive study. Journal of Research in Childhood Education, 29(3), 367-389.

Safitri, D., Syukri, M., \& Yuniarni, D. (2014). Peningkatan Kemampuan Daya Ingat Melalui Permainan Puzzle Pada Anak Usia 5-6 Tahun. Jurnal Pendidikan dan Pembelajaran Khatulistiwa, 3(6).

Suyadi, T. P. A. U. D. (2014). dalam Kajian Neurosains. Bandung: Remaja Rosdakarya, 8.

Ulfah, A. A., \& Rahmah, E. (2017). Pembuatan dan pemanfaatan busy book dalam mempercepat kemampuan membaca untuk anak usia dini di paud budi luhur padang. Ilmu Informasi Perpustakaan Dan Kearsipan, 6(1), 28-37.

Wulandari, D. A. N. (2016). Pengaruh Media Pembelajaran Terhadap Motivasi dan Hasil Belajar Siswa Pada Pembelajaran Kosakata Bahasa Inggris. Paradigma-Jurnal Komputer Dan Informatika, 18(2), 18-24.

Yuliani Nurani, S., \& Bambang, S. (2010). Bermain Kreatif Berbasis Kecerdasan Jamak. Jakarta: Indeks. Pengabdian Beliau Pada PAUD Terwujudkan Pada Temuan. 